
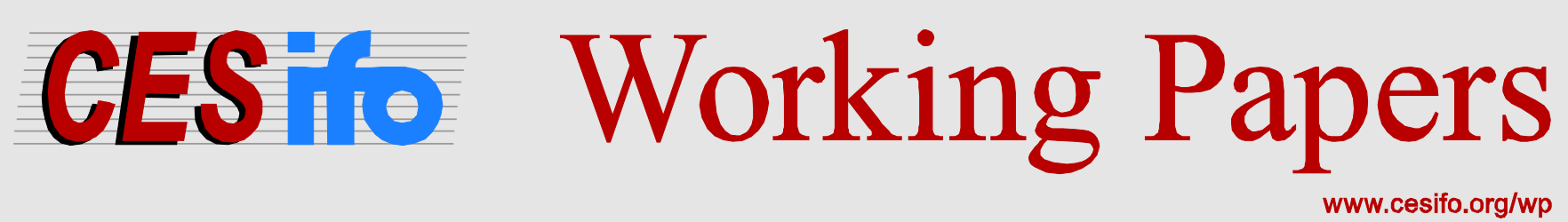

\title{
Illusion of Control and the Pursuit of Authority
}

\author{
Randolph Sloof \\ Ferdinand A. von Siemens
}

CESIFO WORKING PAPER NO. 4764

CATEgORY 13: BEHAVIOURAL ECONOMICS

APRIL 2014

An electronic version of the paper may be downloaded

- from the SSRN website:

- from the RePEc website:

- from the CESifo website:

WWw.SSRN.com

www.RePEc.org

www.CESifo-group.org/wp

\section{CESifo}




\title{
Illusion of Control and the Pursuit of Authority
}

\begin{abstract}
In a laboratory experiment, we measure subjects' willingness to pay for a transparently useless decision right concerning the choice between two real effort tasks. We also elicit for each participant her change in beliefs about the likelihood of receiving her preferred task if she rather than another participant makes the decision. Participants pay more to keep control if they - irrationally - believe that they can increase the probability of getting their preferred task by keeping control. We thus document that illusion of control exists in a controlled environment with monetary incentives, and that illusion of control might affect people's pursuit of authority.
\end{abstract}

JEL-Code: C910, D230, D800.

Keywords: control preferences, illusion of control, allocation of decision rights.

\author{
Randolph Sloof \\ University of Amsterdam \\ Roetersstraat 11 \\ The Netherlands - 1018 WB Amsterdam \\ r.sloof@uva.nl
}

Ferdinand A. von Siemens

Goethe University Frankfurt

Grueneburgplatz 1

Germany - 60323 Frankfurt am Main

vonsiemens@econ.uni-frankfurt.de

April 2014

We are very grateful to Thomas Buser, Holger Herz, Joep Sonnemans, Jeroen van de Ven, and Joël van der Weele for very helpful comments. We thank the priority research area Behavioral Economics of the University of Amsterdam for financial support. 


\section{Introduction}

Authority and control often have clear economic value for those who possess it, since decision power allows individuals to choose the option that best serves their interests. However, the pursuit of authority does not always seem to follow purely rational principles. For example, decision makers often seem to be reluctant to give up authority, even if retaining authority is objectively not in their best interest. This suggests that at least some people value decision rights beyond their purely instrumental value. Fehr, Herz \& Wilkening (2013), Bartling, Fehr \& Herz (2013) and Owens, Grossman \& Fackler (forthcoming) indeed find that a significant fraction of their experimental subjects intrinsically value authority and control.

Yet besides an intrinsic preference for keeping control, there might exist other reasons for why authority is overvalued as compared to its objective instrumental value. One behavioral bias well documented in psychology is illusion of control: people overestimate the extent to which keeping control increases their chances for success, even if outcomes are governed purely by chance. ${ }^{1}$ Such illusory beliefs might provide another driver behind people's desire to keep control; they subjectively believe that the instrumental value of control is larger than it objectively is. In this paper we identify individual subjects' illusory beliefs of control and evaluate whether those subjects with stronger illusory beliefs of control indeed have a stronger desire to keep authority.

In our experiment subjects first gain experience with two real effort tasks: adding numbers and counting letters. One of the two tasks is performed again. Which task depends on the choice between two neutrally labeled and initially unspecified Task A or B. Participants know that Task A and B are connected to the numbers or letters tasks. But they do not know whether Task A corresponds to the numbers task and Task B corresponds to the letters task, or whether it is the other way around. It is common knowledge that nobody knows which task is connected to adding numbers and which task is connected to counting letters, and this is made very clear in the instructions and with the use of control questions. The choice between Task A and B - which induces a transparently random choice between the easy and the difficult task - is either made by the subjects themselves, by a randomly chosen other subject, or by the computer. We measure subjects' beliefs concerning the likelihood of getting

\footnotetext{
${ }^{1}$ See, for example, Langer (1975), Thompson (1999), Fast, Gruenfeld, Sivanathan \& Galinsky (2009), and Fenton-O'Creevy, Nicholson, Soane \& Willman (2003).
} 
their preferred task if they make the choice and if some other participant makes the choice for them. We also measure their willingness to pay for choosing themselves.

Results show that most subjects have rational beliefs - they report that the probability of picking the preferred task equals $50.00 \%$ no matter who chooses. $56.16 \%$ of our participants with entirely rational beliefs are also unwilling to pay for making the decision themselves, but consistent with the existing literature, we do observe intrinsic preferences for control. However, we also find that $26.09 \%$ of our subjects have an illusion of control: they believe that they are more likely to get their preferred outcome, if they rather than another participant choose the task, even though for both them and the other participant the choice is so obviously in the dark. Further, the stronger these illusory beliefs, the more individuals are willing to pay to retain the decision right. The correlation between illusion of control and willingness to pay for control is statistically highly significant ( $p$-values of less than 0.015 ). Finally, our data suggest that at least $43.89 \%$ of the willingness to pay for objectively useless control can be explained by illusion of control. We therefore obtain tentative individual-level evidence that illusion of control does exist and might drive people's pursuit of control. ${ }^{2}$

\section{Related Literature}

Our experiment of course connects to the recent literature on preferences for control and the allocation of authority, see Falk \& Kosfeld (2006), Fehr et al. (2013), Bartling et al. (2013), and Dominguez-Martinez, Sloof \& von Siemens (2014). They find that the allocation of power as such affects behavior. But none of them explicitly looks at the interplay between illusory beliefs and the pursuit of authority. We are therefore more closely related to the following articles that investigate the link between - potentially biased - beliefs with behavior.

In our experiment many subjects hold incorrect beliefs about the probability of picking their preferred task. Further, subjects report the higher a willingness to pay for control, the more their beliefs are biased towards an illusion of control. This resembles Powdthavee \& Riyanto (forthcoming) who find that in their experiment, subjects who buy useless advice bet more on the outcome of coin flips. Advice is not bought for fun or out of curiosity, but is presumably

\footnotetext{
${ }^{2}$ Since we do not exogenously vary illusion of control, we cannot identify a causal link between illusion of control and the pursuit of authority. This holds because our measure of illusion of control can of course be correlated with some unobservable characteristic, which in turn affects the decision to keep control. We therefore have to be careful in drawing strong conclusions from our results.
} 
seen to have instrumental value. Powdthavee \& Riyanto (forthcoming) and we thus find that people act consistently on irrational beliefs. Yet only our paper looks at the link of illusion of control with the pursuit of authority.

Our experiment also connects to Owens et al. (forthcoming). Subjects preview 10 pairs of quiz questions that they and a matched other participant have to answer later. They also report their beliefs regarding the likelihood of getting the answers right. Subjects then choose whether their payoffs should depend on their own answer or on the answer of their match. Many prefer their payoffs to depend on their own answer, although this does not maximize expected payoffs given their own stated probabilities. But the objective probabilities for getting the answers to particular quiz questions right are unknown. Therefore, Owens et al. (forthcoming) cannot study whether illusion of control might drive the pursuit of control for those who believe their own answers to be more likely to be correct than the answers of the other participants.

We finally complement Charness \& Gneezy (2010) who study how investment choices between a safe and a risky asset vary with illusion of control. The success of risky investments is determined by rolling a die. Treatments differ in who rolls the die (subject, experimenter, subject choice) and whether subjects have to pay for rolling the die themselves. Charness and Gneezy observe that $68 \%$ prefer to roll the die if this is for free. Yet only $9 \%$ are willing to pay $\$ 0.50$ for making this choice. This is consistent with the low average willingness to pay for control that we find (18.82 eurocents). However, Charness \& Gneezy (2010) do not measure beliefs. They thus cannot study whether those few paying for control hold illusory beliefs that control has instrumental value.

\section{Experimental Design}

Given its short duration we combined the control experiment with an unrelated experiment. At the start we informed subjects that the session consisted of two independent experiments. Only after they completed the first, subjects received instructions for the second experiment. ${ }^{3}$ We conducted seven sessions with 138 subjects in total. Overall earnings equalled the sum of earnings in the two experiments plus a fixed fee of 3.00 euros. Subjects earned on average 25.00 euros for about 100-110 minutes in total; the control experiment reported upon here took about 20-25 minutes, yielding 7.50 euros on average.

\footnotetext{
${ }^{3}$ Instructions can be found in the appendix. Information on the first experiment is available upon request.
} 
The experiment consisted of three parts. In each part subjects performed a real effort task. In the first part, the task was adding two 3-digit numbers. Each correct answer yielded 10 eurocents. Subjects did not get intermediate feedback; they only learned the overall number of correct answers once 5 minutes were over. In the second part, the task was counting how many times the letters $b, d, p$ and $q$ occurred in a given string of ten letters. These strings of letters consisted of only those four letters. For a correct answer all four numbers had to be correct. Again subjects earned 10 eurocents per correct answer and no intermediate feedback was given. In the third part, subjects either performed the numbers or the letters task for another five minutes. To determine their task, two boxes were shown on the screen, labelled Task A and Task B. Subjects did not know to which tasks these boxes corresponded. So for them Task A corresponding to adding numbers and Task B corresponding to counting letters is equally likely as the other way around. Subjects were informed that they would either choose themselves between Tasks A and B, that another subject would do so for them, or that the computer would select their activity.

We next describe our procedure for measuring subjects' beliefs and their willingness to pay for taking the decision themselves. Subjects made three decisions, corresponding to three different scenarios of how their activity is determined. Ex-post we randomly selected one scenario to determine the activity. In the first scenario, the activity is either determined by the subject's own choice between Task A and B, or by the imposed choice of a randomly selected other participant. Subjects choose their maximum willingness to pay (between 0 and 50 eurocents) to have their own choice implemented. A randomly drawn price between 0 and 50 then determined the actual price, making it optimal for subjects to truthfully report their maximum willingness to pay. In the second scenario, we asked subjects to state their belief that they chose their preferred activity (adding numbers or counting letters) when choosing themselves. Rational beliefs equal $50 \%$ since subjects choose in the dark. Like Owens et al. (forthcoming) we incentivize the revelation of beliefs as follows. After subjects report their beliefs (S\%), the computer drew a random percentage between 0 and $100(\mathrm{C} \%)$. If the draw of $\mathrm{C} \%$ was below the stated belief of $\mathrm{S} \%$, the subject's choice determined the activity. Otherwise, the computer selected the preferred activity with probability C\%. Subjects explicitly stated their preferred activity before they made their choices in the three scenarios. Again it is in the subjects' best interest to report their beliefs truthfully. In the third scenario, we measured a subject's belief that the other randomly matched participant chose the subject's 
preferred activity for him/her in exactly the same way. ${ }^{4}$

To make sure that subjects understood the rules of the experiment, they had to complete control questions before the experiment continued. These questions made it clear that no participant knew which of Task A or B was connected to the numbers and letters tasks. It said explicitly that "The other participant that might choose for you also does not know which task corresponds to adding numbers and which one to counting letters." The control questions also explained with the help of examples the belief elicitation mechanism. The experiment started only once all participants correctly answered the control questions.

At the end of experiment subjects completed a questionnaire on standard background characteristics like age, gender, and type of study. We included several standard questionnaire items to measure subjects' need for autonomy, need for power, and their Machiavellianism as in Gunnthorsdottir, McCabe \& Smith (2002), since these behavioral traits are thought to be related to the pursuit of authority. We also measured subjects' entrepreneurship intentions, since people might want to become entrepreneurs to be autonomous and thus keep control of their life.

\section{Results}

If people have no preferences concerning adding numbers and counting letters, it is irrelevant what task is implemented in the third part of the experiment. Pursuing authority then makes no sense, even if subjects believe that they are more likely to get what they want in case they keep authority. The two tasks were thus chosen so as to make the first task more entertaining and easier than the second. To investigate whether this is indeed the case, we first look at how subjects initially perform in the two tasks. Table 1 summarizes the number of correct answers given in each of the two tasks, as well as the number of attempts. Looking at the correct solutions, adding numbers seems to be easier than counting letters. Subjects correctly complete on average 31.33 calculations, but correctly answer only 13.07 questions counting letters. Only one of the 138 subjects performs better in counting letters. Over 86\% (60\%) of the subjects solve at least 10 (15) calculations more than counting letters. The average difference in performance is 18.26 calculations more. A Wilcoxon signed-rank test comparing

\footnotetext{
${ }^{4}$ Schlag, Tremewan \& van der Weele (2013) discuss various methods for eliciting beliefs. They advise using explicit monetary incentives. The method used here they label as Reservation Probabilities. It is robust to participants' risk aversion.
} 
Table 1: Initial Performance in Real Effort Tasks

\begin{tabular}{lcccccc}
\hline \hline & \multicolumn{3}{c}{ Correct Solutions } & \multicolumn{3}{c}{ Attempts } \\
& Mean & S.D. & Range & Mean & S.D. & Range \\
\hline Numbers & 31.33 & 10.83 & 6 to 66 & 33.86 & 11.08 & 10 to 72 \\
Letters & 13.07 & 3.32 & 4 to 21 & 14.71 & 3.26 & 7 to 23 \\
Numbers - Lettters & 18.26 & 9.87 & -4 to 50 & 19.15 & 9.69 & -1 to 49 \\
\hline \hline
\end{tabular}

Note: Initial average number of correct answers and attempts in the two real-effort tasks adding numbers and counting letters. Number of observations $N=138$.

for each individual the performance in both tasks reveals a statistically highly significant difference ( $p$-value less than 0.001).

Comparing the number of correct answers to the number of attempts, adding numbers is easier in the sense that subjects make fewer mistakes. On average $92 \%$ of the answer are correct for the numbers task, and $89 \%$ of the answer are correct for the letters task. Even though not large, a Wilcoxon signed-rank test comparing for each individual the success rate across tasks reveals a statistically highly significant difference ( $p$-value of 0.015 ). We also ask subjects which task they would prefer if they could choose in the open. 95\% (131 out of 138) preferred the numbers task. To get some indication of intensity, we ask subjects in the ex post questionnaire on a 1 to 7 Likert scale to what extent they liked doing the tasks. The average score for adding numbers is 5.51 whereas for counting letters it is around 2.47. A Wilcoxon signed-Rank test reveals a highly significant difference in distributions ( $p$-value less than 0.001). We conclude that subjects typically prefer adding numbers to counting letters. This provides scope for illusion of control to affect the pursuit of authority, since subjects care for the outcome of the decision.

Our main interest lies in subjects' potentially illusory beliefs and their willingness to pay for an objectively useless control right. Figure 1 shows frequency distributions of beliefs and willingness to pay. The top-left panel depicts the beliefs about successfully choosing the preferred task oneself. The majority of subjects hold rational beliefs, rightly thinking that this likelihood exactly equals $50 \%$. The bottom-left panel gives the belief that a randomly selected other participant picks the subject's preferred option if making the choice. Also here the majority rationally believes this probability to be $50 \%$. The top-right panel displays what 
we define as illusion of control: the additional probability with which subjects believe to be better in choosing their preferred option when choosing themselves rather than a randomly selected other participant. $65.94 \%$ subjects have no illusion of control. However, a sizable fraction of $26.09 \%$ of subjects falsely believe that they can increase their success probability by retaining the objectively useless decision right. Only $7.97 \%$ of participants believe that others make better choices than themselves. A Wilcoxon signed-rank test rejects that the distribution of illusion has a median of zero ( $p$-value less than 0.001 ). Illusion of control thus seems to reflect a systematic behavioral bias and not only noise in the belief statements.

The bottom-right panel gives the willingness to pay for making the task choice oneself. $40.58 \%$ of participants state the rational prediction of zero. However, we observe many participants with a strictly positive willingness to pay for control. Noise or confusion does not seem to drive the willingness to pay for control. Otherwise, we should observe predominantly small deviations from the rational benchmark of zero, and no spike of $18.84 \%$ at the maximum amount subjects were allowed to spend to obtain the decision right. The average willingness to pay is $18.82 .^{5}$

Overall, we find that the majority of people are willing to pay small but positive amounts to keep an objectively useless control right. In the following we study what could induce this behavior. We focus first on the $52.90 \%$ of subjects who have fully rational beliefs, that is, those who state that the probability of getting their preferred task is $50 \%$, no matter who chooses. These subjects do not believe the decision right to have any instrumental value. They nevertheless report an average willingness to pay of 15.14. Paying for control thus at least partially reflects intrinsic preferences for control as argued by Fehr et al. (2013), Bartling et al. (2013) and Owens et al. (forthcoming).

\footnotetext{
${ }^{5} 18.82$ points corresponds to 18.82 eurocents. The small amounts involved in our experiment may suggest that the amount of money lost due to preferences for control or illusory beliefs are negligible in practice. We discuss this important argument in our conclusion.
} 
Figure 1: Beliefs, Illusion of Control, and Willingness to Pay.
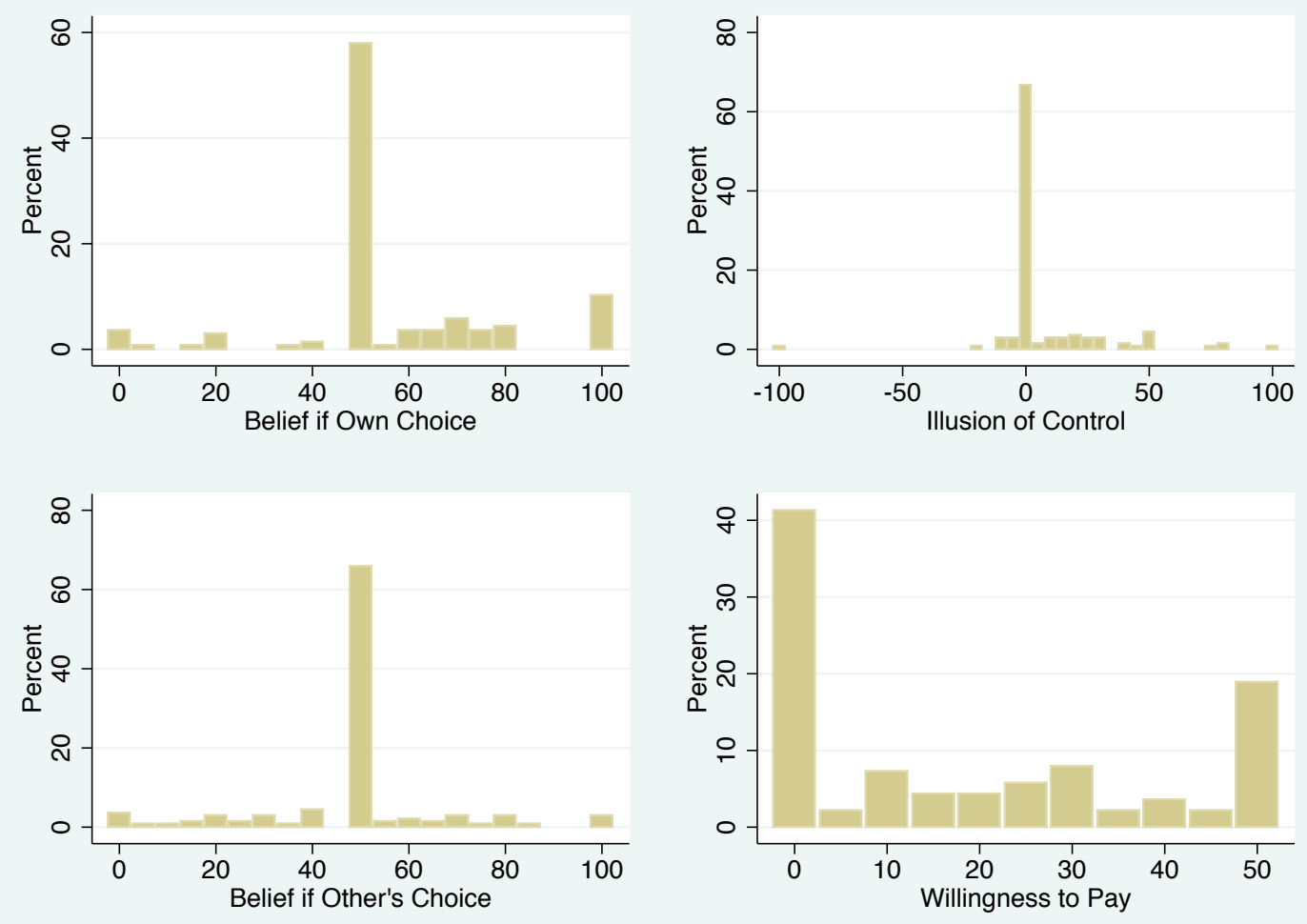

But apart from intrinsic control preferences, illusory beliefs could induce participants to pay for choosing between Task A and B oneself. We first look at whether those participants with stronger illusion of control tend to pay more to keep control. The Spearman rank correlation between illusory beliefs of control and willingness to pay equals 0.19 and it is significantly different from zero ( $p$-value of 0.02 ). Moreover, those with positive illusion of control report a higher average willingness to pay than those with no or negative illusion of control (26.42 versus 16.14). A Mann-Whitney ranksum test yields that the differences in willingness to pay are statistically significant ( $p$-value of 0.002 ). It thus appears that those bid higher who think that they are better in making the random task choice themselves rather than somebody else. Figure 2 illustrates this by means of a scatter plot of the average willingness to pay for different levels of illusory beliefs. In this figure illusory beliefs that fall into 20 intervals of length ten are grouped together; besides these intervals, those observations with zero illusion of control constitutes a separate class. We plot the average willingness to pay for these groups of illusion of control. The size of the circles represents the number of observations from that 
class. We observe a clear upwards trend: participants with stronger illusion of control tend to state a higher willingness to pay for control. ${ }^{6}$

Figure 2: Illusion of Control and Willingness to Pay.

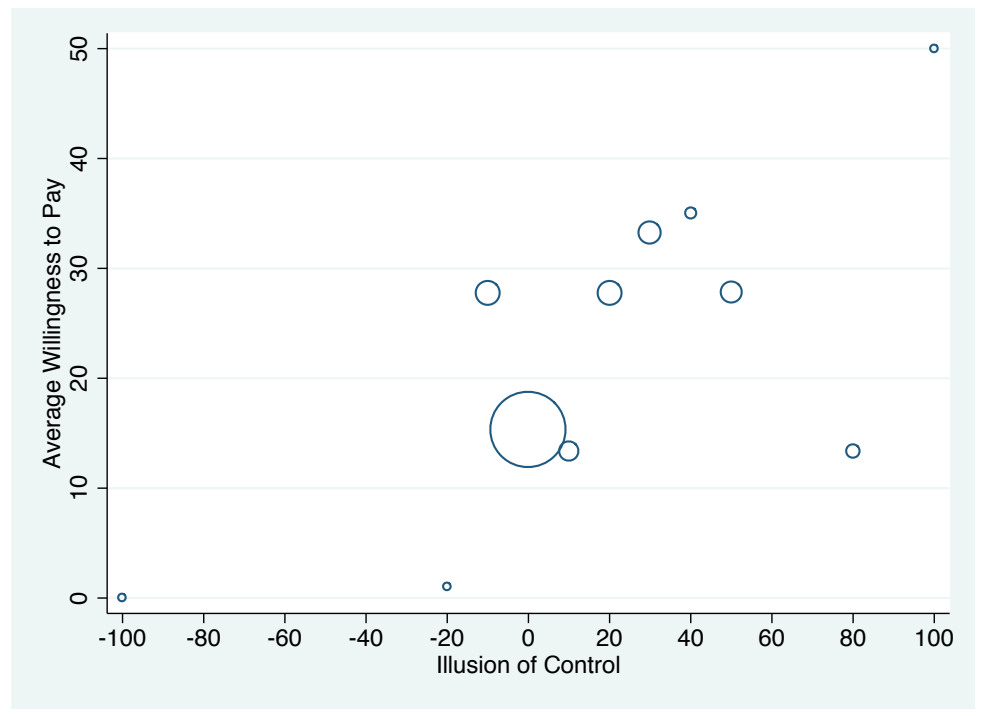

We next study the link between illusion of control and willingness to pay for control with the help of regression analysis. Columns (1)-(3) in Table 2 present two-sided Tobit estimates of the willingness to pay for making the decision oneself. In the first specification we only include illusion of control as independent variable. In the second specification we add two variables that reflect the potential benefits of making a better choice. We initially asked participants directly which task they would prefer for part three of the experiment. We use these answers to construct the following measures. Monetary Task Preference equals the expected increase in correct answers if participants get their preferred task rather than the other task. We compute this difference via the actual performance of each participant in part one and two of the experiment. Participants need not prefer the task which gives them a higher monetary payoffs, yet only $4.35 \%$ have a negative monetary task preference. In addition, we define Stated Task Preference as by how much participants prefer their initially preferred task in the ex-post questionnaire (difference in Likert scores). The questionnaire answers need not be consistent with the initial stated task preference, but only $5.80 \%$ of observations are negative. We are thus confident that our measures capture monetary and intrinsic task preferences. In the regressions we also include dummies to control for gender and study background.

\footnotetext{
${ }^{6}$ The figure reveals two extreme observations potentially causing the positive link between illusion of control and willingness to pay. Our main results are robust to the exclusion of these extreme observations.
} 
Table 2: Tobit Regressions of Willingness to Pay and Illusion of Control

\begin{tabular}{|c|c|c|c|c|c|}
\hline & \multicolumn{3}{|c|}{ Willingness To Pay } & \multicolumn{2}{|c|}{ Illusion of Control } \\
\hline & (1) & $(2)$ & $(3)$ & (4) & $(5)$ \\
\hline \multirow[t]{2}{*}{ Illusion of Control } & $0.50^{* *}$ & $0.52^{* *}$ & $0.52^{* *}$ & & \\
\hline & $(0.20)$ & $(0.21)$ & $(0.21)$ & & \\
\hline \multirow[t]{2}{*}{ Monetary Task Preference } & & 0.18 & 0.10 & $-0.30^{*}$ & $-0.34^{*}$ \\
\hline & & $(0.38)$ & $(0.40)$ & $(0.17)$ & $(0.17)$ \\
\hline \multirow[t]{2}{*}{ Stated Task Preference } & & 1.63 & 2.37 & -0.47 & -0.18 \\
\hline & & $(1.94)$ & $(1.98)$ & $(0.86)$ & $(0.87)$ \\
\hline \multirow[t]{2}{*}{ Economics Student } & & -1.79 & -2.82 & $7.62^{* *}$ & $8.81^{* *}$ \\
\hline & & $(8.59)$ & $(8.65)$ & $(3.77)$ & $(3.76)$ \\
\hline \multirow[t]{2}{*}{ Male } & & -7.29 & -6.68 & -5.72 & -5.35 \\
\hline & & $(7.96)$ & $(8.22)$ & $(3.53)$ & $(3.64)$ \\
\hline \multirow[t]{2}{*}{ Machiavelli } & & & 0.44 & & $0.45^{* *}$ \\
\hline & & & $(0.50)$ & & $(0.22)$ \\
\hline \multirow[t]{2}{*}{ Autonomy } & & & -1.12 & & -0.33 \\
\hline & & & $(1.03)$ & & $(0.45)$ \\
\hline \multirow[t]{2}{*}{ Power } & & & -2.32 & & -0.37 \\
\hline & & & $(1.52)$ & & $(0.64)$ \\
\hline \multirow[t]{2}{*}{ Entrepreneurship Intentions } & & & 3.13 & & -0.64 \\
\hline & & & $(2.33)$ & & (1.01) \\
\hline \multirow[t]{2}{*}{ Constant } & 6.85 & 3.69 & 33.31 & $11.86^{* * *}$ & -5.43 \\
\hline & $(4.48)$ & (10.13) & (44.68) & $(4.34)$ & (19.94) \\
\hline$\chi^{2}$ & 6.87 & 9.07 & 15.01 & 10.87 & 16.36 \\
\hline
\end{tabular}

Tobit regressions of willingness to pay and illusion of control. We have $N=138$ observations. Standard errors in parenthesis. ${ }^{*} p<0.10,{ }^{* *} p<0.05,{ }^{* * *} p<0.01$. 
The estimates reveal that only the coefficientfor Illusion of Control is (positively) statistically significant. SubjThe other variables do not have any significant impact. In specification (3) we include the psychological traits measured in the ex-post questionnaire. ${ }^{7}$ None of these reaches significance. It is frequently argued that entrepreneurs start their own ventures to keep control over their working life, see for example Simon, Houghton \& Aquino (1999) and Fuchs-Schündeln (2009). Intentions to become an entrepreneur has the expected positive effect. But the effect is not statistically significant.

We thus find empirical evidence suggesting that participants with higher illusion of control have a higher willingness to pay for control. There is no significant link between willingness to pay for control and our control variables. We finally want to get some feeling for the extent to which participants' willingness to pay for control might be driven by intrinsic preferences for control, and to what extent it might be driven by illusion of control. To this end we compute for each participant what we call the perceived instrumental monetary value of control. For the latter we multiply the monetary task preference by the illusion of control, and thus by the increase in getting your preferred outcome, if you make the decision yourself rather than some other participant. This defines a lower bound since it does not account for preferences concerning the tasks other than the monetary consequences (some might simply prefer adding numbers to counting letters). The average perceived instrumental monetary value is 8.26. Setting this in relationship with the average willingness to pay of 18.82 , our data therefore suggest that at least $43.89 \%$ of participants' willingness to pay for control might be explained by illusion of control.

\section{Discussion}

One concern with the strictly positive average willingness to pay for control is that subjects make a positive bid "just to do something" or that they wrongly believe that anything that can be bought in the experiment "must have some value." Illusion of control instead implies that participants wrongly believe to know which task choice yields them the desired task. Do those who pay for control follow some "cunning plan" and how reasonable is this plan? To find this out, we next look at the link between willingness to pay and the actual choices between Task A and B. Subjects always started with adding numbers and then proceeded to

\footnotetext{
${ }^{7}$ We use factor analysis to create one-dimensional measures from our questionnaire items. We drop locus of control due to low internal consistency (Cronbach's Alpha of 0.46).
} 
counting letters. They might thus erroneously believe - maybe subconsciously - that Task A corresponds to adding numbers, and Task B to counting letters. Those who hold these beliefs and prefer adding numbers should choose Task A. ${ }^{8} 80.15 \%$ of participants who prefer adding numbers indeed choose Task A. A binomial test rejects the hypothesis that individuals equally randomize between the tasks ( $p$-value less than 0.001$)$. It could thus be that many subjects believe that Task A is most likely to give them their preferred activity.

Next, we check whether subjects might reasonably believe that they are more likely to get Task A if they choose themselves. We therefore compare the probability of getting Task A if subjects choose themselves rather than if somebody else chooses for them. Only $67.94 \%$ of participants who prefer adding numbers choose Task A for other participants. A Wilcoxon signed-rank test reveals that those who prefer adding numbers are significantly more likely to choose Task A for themselves than for others ( $p$-value less than 0.01). If subjects take their own choices for others as indicative for the others' choices for them, subjects might thus believe that they can increase the probability for getting Task A by keeping control. Finally, if participants pay for control because they want Task A, then those who pay more should be more likely to select Task A. Task A is chosen by $84.15 \%$ of those with strictly positive, and by $71.43 \%$ of those with zero willingness to pay. However, a Fisher's exact test shows that this difference is marginally insignificant ( $p$-value of 0.12 ).

Overall, our data on task choices does not suggest that the observed bidding behavior is driven by noise in the decision making process. It rather seems that participants buy control to make sure to get Task A, possibly in the erroneous hope that this increases the probability for getting the adding numbers task. We consider this as evidence for the presence of illusion of control.

Since illusory beliefs are strongly connected with the willingness to pay for control, we next investigate what could be underlying determinants. The psychology literature identifies need for control as personal factor that increases illusion of control, see Burger \& Cooper (1979) and Thompson (1999). Need for control is partially captured by our variables Monetary and Stated Task Preferences. We also elicit gender, field of study, and several psychological traits arguably related to control preferences. In the specifications (4) and (5) reported in Table 2,

\footnotetext{
${ }^{8}$ The reverse holds for those who prefer counting letters. Only $5.07 \%$ of participants prefer counting letters. We thus restrict attention to those who prefer adding numbers because of a lack of observations.
} 
Monetary Task Preferences has a (marginally) significant negative link with illusory beliefs. The coefficient of Stated Task Preferences is insignificant. Gender does not have a significant impact. Economics and business students tend to have stronger illusory control beliefs than other students have. We have no idea why this should be the case. Results of specification (5) show that from the psychological traits, only Machiavellianism has a significant correlation with illusory beliefs. This suggests that people who can detach themselves from emotions and moral norms to manipulate others tend to overestimate the extent to which they can control their environment. But overall we find no convincing explanations - also not from psychology - for our observed illusion of control.

One concern regarding our measures with illusion of control might therefore be that subjects did not understand the incentive-compatible mechanism to elicit their beliefs. Schlag et al. (2013) summarize the debate in the literature about whether subjects understand stochastic payoff schemes. If participants are confused, our measure of illusion of control reflects only noise in their decision making process. We do not believe that this is the case. First, the observed distribution of illusion of control is not consistent with pure noise, as already mentioned before. Second, noise cannot explain the positive correlation between willingness to pay and illusory beliefs. Thirdly, before the incentivized-beliefs experiment, we conducted sessions (with $N=114$ subjects) with non-incentivized beliefs. ${ }^{9}$ Scenarios two and three were absent, and scenario one always applied. After subjects had chosen their willingness to pay for control, they were asked their beliefs on the likelihood of success if they and if the other subject would choose. Repeating our statistical analysis for the sessions with nonincentivized beliefs yields similar results. ${ }^{10}$ In particular, we find a robust and significant

\footnotetext{
${ }^{9}$ We also ran two sessions in which we did not ask for beliefs. We exclude these sessions from the analysis, since in these we cannot measure participants' illusion of control.

${ }^{10}$ The only two major difference in findings are that with non-incentivized beliefs i) subjects have a lower average willingness to pay for control, and ii) they report on average a negative level of illusion of control. The latter implies a negative average perceived instrumental value of control. These differences could have several reasons. First, the incentive-compatible belief elicitation makes the probabilities to get their preferred outcomes more salient and thus more important in the decision making process. Second, we ran the nonincentivized beliefs experiment after a different initial experiment. Thirdly, we used a different scale when measuring subjects' willingness to pay for control in the experiment with incentivized beliefs. Finally, in the incentivized beliefs experiments scenario one only applied in one third of the cases, so actual payments for control were made with a probability of $33 \%$ at most. Due to these differences, data from both experiments cannot be jointly analyzed. Following Schlag et al. (2013) we have more faith in our incentivized belief measures. For that reason we focus on that data in this study.
} 
positive correlation between illusion of control and willingness to pay. We consequently do not believe sheer misunderstanding to drive our results.

\section{Conclusion}

Our experimental findings suggest that illusion of control might lead subjects to overvalue decision rights. In the following we explain how our results could have important implications for practice, although we find that people are not willing to pay large amounts for control in response to their illusory beliefs.

Langer (1975) argues that people entertain an illusion of control since they wrongly assign a particular situation skill-related properties. Our experimental setup provides a strong test of illusion of control, because we make it clear in the instructions that all subjects make fully uninformed decisions. We might thus well observe more illusion of control in real-life situations in which it is more rational to believe that some people can control outcomes. This argument is taken up by Fenton-O'Creevy et al. (2003) who find that investment bank traders with stronger illusory beliefs of control - measured in a computerized control task have lower performance ratings and earnings. Furthermore, small levels of initial illusion of control might be amplified over time. Fast et al. (2009) suggest that possesion of power leads to illusory beliefs. Pfeffer, Cialdini, Hanna \& Knopoff (1998) show that managers perceive outcomes to be more positive, if they believe to be more involved in the work process. This can create a feedback loop. Those with weak illusory beliefs or slight intrinsic preferences for control might initially be drawn towards positions with authority. Once in power, people believe to have the ability and almost an obligation to intervene in organizational decisions. Foss (2003) documents such temptation for managerial meddling. Consequently, those in power develop stronger illusion of control. This fuels their defense of existing authority or pursuit of further decision rights.

In the real world, the effects of small initial predispositions for illusion of control could thus be substantial, so that incompetent and irrational people end up entrenched in important positions with extensive decision rights. Future research might investigate the evolution of illusion of control. This could help organizations to influence their employees' illusory control beliefs, the smooth delegation of authority, and thus ultimately the quality of organizational decisions. 


\section{References}

Bartling, B., Fehr, E. \& Herz, H. (2013). The intrinsic value of decision rights, CESifo Working Paper No. 4252 .

Benoît, J.-P. \& Dubra, J. (2011). Apparent overconfidence, Econometrica 79: 1591-1625.

Burger, J. M. \& Cooper, H. M. (1979). The desirability of control, Motivation and Emotion 3(4): 381-393.

Charness, G. \& Gneezy, U. (2010). Portfolio choice and risk attitudes: An experiment, Economic Inquiry 48(1): 133-146.

Dominguez-Martinez, S., Sloof, R. \& von Siemens, F. A. (2014). Monitored by your friends, not your foes: Strategic ignorance and the delegation of real authority, Games and Economic Behavior 85: 289-305.

Falk, A. \& Kosfeld, M. (2006). The hidden costs of control, American Economic Review 96(5): 1611-1630.

Fast, N. J., Gruenfeld, D. H., Sivanathan, N. \& Galinsky, A. D. (2009). Illusory control: A generative force behind power's far-reaching effects, Psycholgical Science 20(4): 502-508.

Fehr, E., Herz, H. \& Wilkening, T. (2013). The lure of authority: Motivation and incentive effects of power, American Economic Review 103(4): 1325-1359.

Fenton-O'Creevy, M., Nicholson, N., Soane, E. \& Willman, P. (2003). Trading on illusions: Unrealistic perceptions of control and trading performance, Journal of Occupational and Organizational Psychology 76: 53-68.

Foss, N. J. (2003). Selective intervention and internal hybrids: Interpreting and learning from the rise and decline of the oticon spaghetti organization, Organization Science 14(3): 331-349.

Fuchs-Schündeln, N. (2009). On preferences for being self-employed, Journal of Economic Behavior and Organization 71(2): $162-171$.

Gunnthorsdottir, A., McCabe, K. \& Smith, V. L. (2002). Using the machiavellilan instrument to predict trustworthiness in a bargaining game, Journal of Economic Psychology 23: 4966. 
Langer, E. J. (1975). The illusion of control, Journal of Personality and Social Psychology 32: $311-328$.

Owens, D., Grossman, Z. \& Fackler, R. (forthcoming). The control premium: A preference for payoff autonomy, American Economic Journal: Microeconomics .

Pfeffer, J., Cialdini, R. B., Hanna, B. \& Knopoff, K. (1998). Faith in supervision and the self-enhancement bias: Two psychological reasons why managers don't empower workers, Basic and Applied Social Psychology 20(4): 313-321.

Powdthavee, N. \& Riyanto, Y. E. (forthcoming). Would you pay for transparently useless advice? A test of boundaries of beliefs in the folly of predictions, Review of Economics and Statistics .

Schlag, K., Tremewan, J. \& van der Weele, J. (2013). A penny for your thoughts: A survey of methods for eliciting beliefs, mimeo, University of Amsterdam .

Simon, M., Houghton, S. M. \& Aquino, K. (1999). Cognitive biases, risk perception, and venture formation: How individuals decide to start companies, Journal of Business Venturing 15: 113-134.

Thompson, S. C. (1999). Illusion of control: How we overstimate our personal influence, Current Directions in Psychological Science 8(6): 187-190. 


\section{Instructions Illusion of Control and the Pursuit of Authority}

Thank you for participating in this experiment. The amount of money you earn depends upon the decisions you and the other participants make. Today's session consists of two separate experiments: Experiment 1 and Experiment 2. These experiments are completely separated. Thus, in each experiment you will interact with different individuals, and your actions in one experiment will have no consequences at all in the other experiment.

In each of the two experiments you can earn points. The conversion rate is such that 1 point corresponds with 1 eurocent (so that 100 points equals 1 euro). Your overall earnings equal the sum of your points earned in the two experiments.

We will pay out your overall earnings in cash after you have completed both experiments and filled out a final questionnaire. We ensure that your final earnings remain confidential: no other participant will learn your final earnings.

Below you will find the instructions for Experiment 1. Instructions for Experiment 2 follow after the first experiment has been completed. Please do not communicate with other participants during the session. If you have a question, please raise your hand. The experimenter will then come to your table to answer your question in private.

\section{Experiment 1}

The instructions for experiment 1 are available from the authors upon request.

\section{Experiment 2}

Experiment 2 consists of three parts. In each part you can earn points by performing a certain activity during five minutes. Your total earnings from Experiment 2 equal the sum of earnings in all three parts and are added to your earnings from Experiment 1. Below you will find the instructions for parts one and two. Instructions for part three will be handed out after part two has been completed.

\section{Part One of Experiment 2}

In part one the individual effort task consists of adding two 3-digit numbers. As an example:

$$
481+729=?
$$

You have to fill in an answer and then proceed to the next calculation. You receive 10 points per correct calculation made. You do not get feedback on each individual calculation, that is, whether your answer to a particular calculation is right or wrong. But you will learn the total number of correct calculations that you made immediately after part one is over. In total you have 5 minutes to make the calculations. 


\section{Part Two of Experiment 2}

In part two the individual effort task consists of counting how many times the different letters $b, d$, $\mathrm{p}$ and $\mathrm{q}$ occur in a string of ten letters. As an example:

$$
\begin{aligned}
& \text { b q q } d d b p q p \\
& \text { Number of letters } b=\text { ? } \\
& \text { Number of letters } d=\text { ? } \\
& \text { Number of letters } p=\text { ? } \\
& \text { Number of letters } q=\text { ? }
\end{aligned}
$$

For a correct answer all four numbers must be correct. Also note that you have to enter 0 if this is the correct number of letters. You receive 10 points per correct answer. You do not get feedback on each individual string, that is, whether your answer for a particular string is right or wrong. But you will learn the total number of correct strings that you made immediately after part two is over. In total you have 5 minutes to count letters.

\section{Part Three of Experiment 2}

In part three the individual effort task is either adding numbers as in part one, or counting letters as in part two. You will again spend five minutes on one of these activities. Which activity this will be is determined as follows. There are Task A and Task B. One task corresponds to adding numbers, the other task corresponds to counting letters. You do not know, however, which task corresponds to adding numbers and which one to counting letters.

The activity you are going to perform is either given by your own choice between Task A and B, by another participant in the experiment who makes the choice between Task A and B for you, or selected by the computer. The other participant that might choose for you also does not know which task corresponds to adding numbers and which one to counting letters.

You first choose whether you would prefer adding numbers or counting letters if you could choose in the open. You then indicate which task (either Task A or B) you would like in case you can make the decision yourself, and which task you would like to impose on another participant in case that participant cannot choose for him- or herself (again either A or B).

You next make three decisions, corresponding to three different scenarios of how your task and thus your activity may be determined. After you have made these decisions, one of the three scenarios is chosen at random. Your decision in the selected scenario then determines the task and thus the activity that you are going to perform. 
Scenario 1: Own choice or other participant's choice

In this scenario your activity is either given by your own choice between Task A and Task B, or by the imposed choice of another participant that has made the choice between Task A and B for you. Your decision is to set the maximum price $P$ that you are willing to pay for having your own choice implemented. Your maximum price can be between 0 and 50 points. After you have chosen your maximum price the computer draws a random number that is denoted by $R$. This number gives the actual price. Any number for $R$ between 0 and 50 points is equally likely. If $R$ is below or equal to your maximum price, your own choice will determine your task. You then have to pay $R$ points. If the actual price $R$ is above your maximum price $P$, the other participant's choice determines your task. In this case you do not have to pay the price $R$.

This procedure may seem complicated, but what it means for you is simple: it is in your best interest to state your true maximum price. This holds because with your stated maximum willingness to pay you do not influence the actual price you have to pay, since this price is drawn randomly. Rather you only indicate whether you are willing to pay a given randomly drawn price to get your own task choice implemented.

\section{Scenario 2: Own choice or computer selection}

In this scenario your activity is either given by your own choice between Task A and Task B, or selected by the computer. Your decision in this scenario is to indicate the probability $S$ with which you think that you have chosen your preferred activity (adding numbers or counting letters) by having chosen your task (Task A or B). $S$ must be between $0 \%$ and $100 \%$. After you have chosen $S$ the computer draws a random number that is denoted by $C$. This number gives the probability with which the computer selects your preferred activity (either adding numbers or counting letters). The computer knows you preferred activity from your own previous answer. Any number for $C$ between $0 \%$ and $100 \%$ is equally likely. If $C$ is below or equal to your own probability $S$ of getting what you prefer, your own choice will determine your task and thus your activity. But if the computer is better in selecting your preferred activity, so if $C$ is larger than $S$, the computer selects your preferred activity with probability $C$ (and the other activity with the remaining probability $100-C$ ).

This procedure may seem complicated, but what it means for you is again simple: it is in your best interest to state your true belief of the probability that you have chosen your preferred activity by having chosen between Task A and B.

\section{Scenario 3: Other participant's choice or computer selection}

In this scenario your activity is either determined by another participant that has made the choice between Task A and B for you, or it is selected by the computer. Your decision in this scenario is to indicate the probability $O$ with which you think the other participant has chosen your preferred activity (adding numbers or counting letters) by having chosen your task (Task A or B). $O$ must be between $0 \%$ and $100 \%$. After you have chosen $O$ the computer draws a random number that is denoted by $C$. This number gives the probability with which the computer selects your preferred activity. The computer knows you preferred activity from your own previous answer. Any number for $C$ between $0 \%$ and $100 \%$ is equally likely. If $C$ is below or equal to the probability $O$ of the other participant imposing on you what you prefer, the other participant's choice will determine your task and thus your activity. But if the computer is better in selecting your preferred activity, so 
if $C$ is larger than $O$, the computer selects your preferred activity with probability $C$ (and the other activity with the remaining probability $100-C$ ).

This procedure may seem complicated, but what it means for you is again simple: it is in your best interest to state your true belief of the probability that the other participant has chosen your preferred activity by having chosen between Task A and B for you.

After making your choices in each of the three scenarios, one scenario will be selected at random. You will then find out how your task and thus your activity is determined: either by your own choice, imposed on you by another participant, or selected by the computer. You then have 5 minutes to work on the task. As before you receive 10 points for every correct answer.

\section{Control Questions}

1. Is the following statement correct? Suppose in the end I can choose between Task A and Task B. Then I know which of these tasks corresponds to adding numbers and which one corresponds to counting letters. [ false ]

2. Is the following statement correct? Suppose in the end another participant chooses between Task A and B for me. Then that person knows which of these tasks corresponds to adding numbers and which one corresponds to counting letters. [ false ]

3. Is the following statement correct? Suppose in Scenario 1 I choose a maximum price of 20 points and the actual price turns out to be 15 points, my own choice between Tasks A and B determines my task and I pay a price of 20 points. [ false ]

4. Is the following statement correct? Suppose in Scenario 1 I choose a maximum price of 20 points and the actual price turns out to be 25 points. Then the other participant's choice between Tasks A and B determines my task. [ true ]

5. Is the following statement correct? Suppose in Scenario 2 I indicate that I believe that the probability equals $80 \%$ that the task I have chosen (A or B) corresponds to my preferred activity (numbers or letters). The computer draws a random number equal to $\mathrm{C}=70 \%$. The computer then selects the task I will perform and I will get my preferred activity with $70 \%$ probability. [ false ]

6. Is the following statement correct? Suppose in Scenario 3 I indicate that I believe the probability equals $20 \%$ that the task the other participant has chosen for me (A or B) corresponds with my preferred activity (numbers or letters). The computer draws a random number equal to $\mathrm{C}=40 \%$. The computer then selects the task I will perform and I will get my preferred activity with $40 \%$ probability. [ true ] 